\title{
Analysis of Input and Output Ripples of PWM AC Choppers
}

\author{
Pekik Argo Dahono, Dessy Amirudin, Arwindra Rizqiawan \& Deni
}

School of Electrical Engineering and Informatics. Institute of Technology Bandung

\begin{abstract}
This paper presents an analysis of input and output ripples of PWM AC choppers. Expressions of input and output current and voltage ripples of single-phase PWM AC choppers are first derived. The derived expressions are then extended to three-phase PWM AC choppers. As input current and output voltage ripples specification alone cannot be used to determine the unique values of inductance and capacitance of the LC filters, an additional criterion based on the minimum reactive power is proposed. Experimental results are included in this paper to show the validity of the proposed analysis method.
\end{abstract}

Keywords: AC Chopper; LC filter; PWM; Ripple; Voltage regulator.

\section{Introduction}

A regulated ac power supply is used in various applications. Most of ac voltage regulators are thyristorized phase-control $\mathrm{AC}$ voltage regulator. This kind of ac voltage regulator is simple, robust, and suitable up to high-power applications. The main drawbacks of this kind regulator are high current harmonics and low power-factor on the input current and high output voltage harmonics [1-2]. In order to solve these problems, various new types of ac voltage regulator were proposed [3-10]. In general, these new ac voltage regulators can be classified into direct and indirect methods. In the indirect method, the ac input voltage is first rectified and the result is reconverted into a controllable ac output voltage. The main advantage of indirect method is the output voltage can be controlled independently to the input voltage. The double conversion process, however, makes this approach has low efficiency. The direct method is usually implemented by using a Pulse Width Modulated (PWM) AC chopper. As the power is processed only once, the efficiency is higher than the indirect method. The main disadvantage of the PWM AC chopper is the output voltage frequency cannot be different to the input frequency. Though a lot of works were published, only a few papers have reported analysis of the input and output ripples. These methods are based on Fourier analysis and, therefore, accurate results and general conclusion cannot be obtained without a lot of complex computation. Ripple analysis is important in the design of the required LC filters. A proper design is important as the LC filter takes the significant volume of an AC chopper. 
This paper presents an analysis of input and output ripples of PWM AC choppers. Expressions of input and output current and voltage ripples of singlephase PWM AC choppers are first derived. The analytical form of the derived expressions make Fourier analysis and the associated complex computation are not required. The derived expressions are then extended to three-phase PWM AC choppers. As input current and output voltage ripples specification alone cannot be used to determine the unique values of inductance and capacitance of the LC filters, an additional criterion based on the minimum reactive power is proposed. Simulated and experimental results show the validity of the proposed analysis method.

\section{PWM AC Choppers}

A PWM AC chopper can be considered as the extension of the DC chopper. Thus, the topology that is used in a PWM AC chopper can also be a buck, boost, buck-boost, or Cuk type. In this paper, the discussion is limited to bucktype PWM AC choppers. The schemes of single phase and three-phase buck PWM AC choppers are shown in Figure 1. LC filters are connected on the input and output sides of $\mathrm{AC}$ choppers to reduce the generated harmonics. If the switching frequency is high the required LC filters can be very small.

Various modulation techniques were developed to control the PWM AC choppers. The most commonly used, however, is the one that is called carrierbased PWM. Figure 2 shows the carrier-based modulation technique that commonly used to control a single-phase PWM AC chopper. In this technique, $\mathrm{S} 1$ and $\mathrm{S} 2$ are turned $\mathrm{ON}$ during active modes, while $\mathrm{S} 3$ and $\mathrm{S} 4$ are turned $\mathrm{ON}$ during freewheeling modes. When switches $\mathrm{S} 1$ and $\mathrm{S} 2$ are turned $\mathrm{ON}$ (switches $\mathrm{S} 3$ and $\mathrm{S} 3$ are turned OFF), the voltage $v_{b}$ is equal to the input voltage $v_{i}$ and the input current $i_{i}$ is equal to the output inductor current $i_{L}$. When switches $\mathrm{S} 1$ and $\mathrm{S} 2$ are turned OFF (switches S3 and S4 are turned ON), both the load voltage $v_{b}$ and input current $i_{i}$ are equal to zero. The ON and OFF signals for the switching devices are obtained by comparing a reference signal to a high-frequency triangular carrier signal. The magnitude of the fundamental load voltage can be controlled by controlling the amplitude of reference signal. When the carrier frequency is much higher than the fundamental source voltage, the ripple components of source current and load voltage can be filtered easily by using small LC filters which are connected on the input and output sides. 


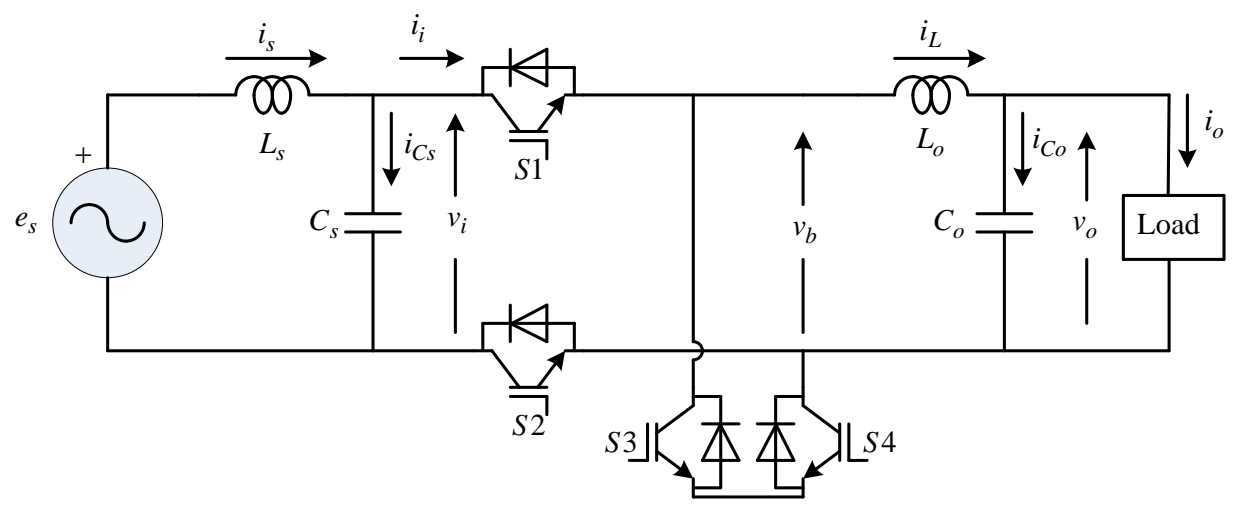

(a)

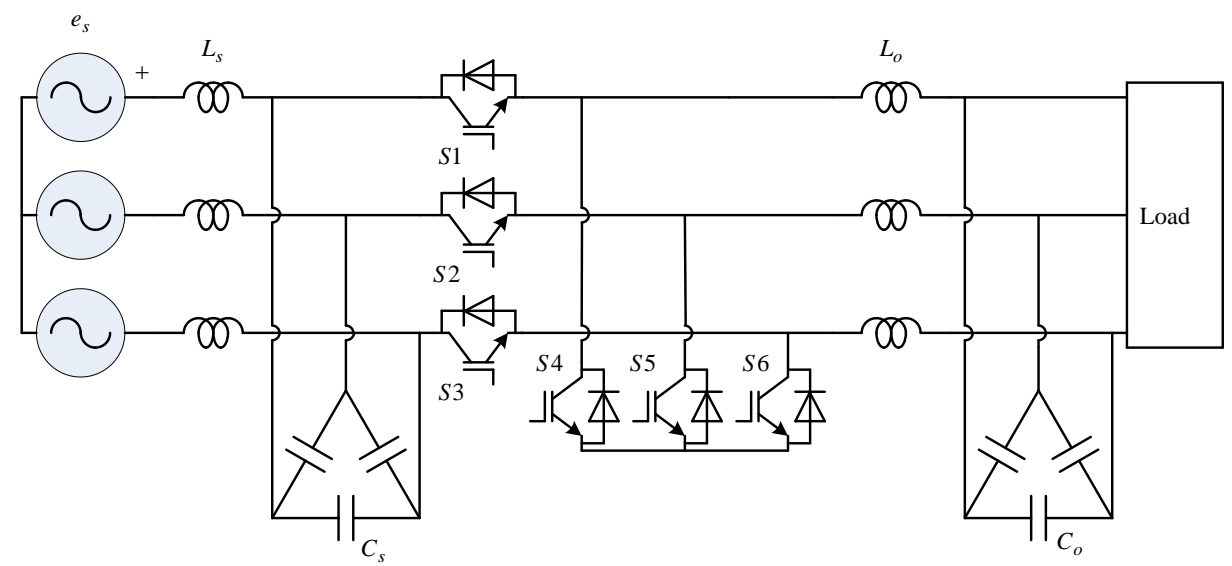

(b)

Figure 1 Scheme of (a) single-phase and (b) three-phase AC choppers.

In the following sections, analysis of input and output ripples of PWM AC choppers will be presented. In this analysis, the following assumptions are used:

- The carrier frequency is much higher than the fundamental source voltage frequency.

- The load is a linear load.

- The switching devices are assumed as ideal switches.

- The LC filter parameters are constants. 


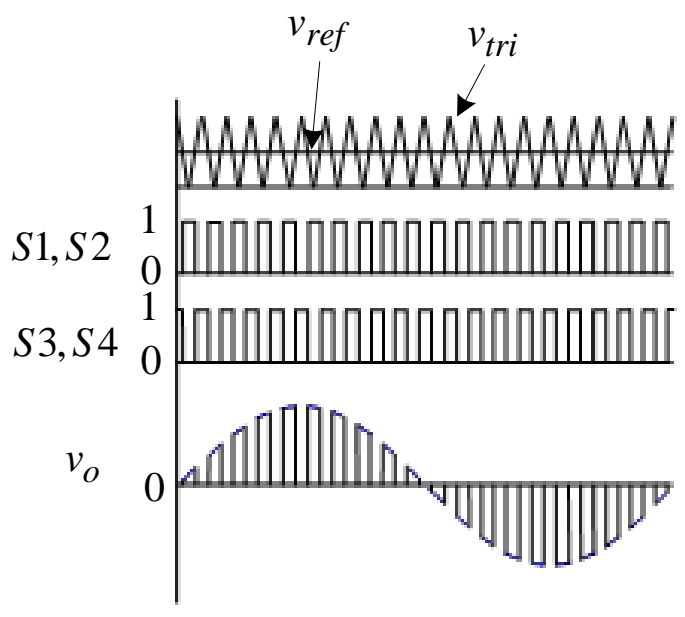

Figure 2 PWM Technique for single-phase AC chopper.

\section{Ripple Analysis of Single-Phase AC Chopper}

\subsection{Output Ripple Analysis}

Output ripple analysis of single-phase AC chopper is first discussed here. The analysis is limited to continuous conduction mode only. For the purpose of output ripple analysis, the voltage ripple across the input filter capacitor is neglected. It is also assumed that voltage across input capacitor, $\mathrm{C}_{\mathrm{s}}$, is equal to the source voltage. Thus,

$$
v_{i}=\sqrt{2} E_{s} \sin \theta
$$

where $E_{s}$ is the rms value of the source voltage. From the AC chopper circuit in Figure 1(a), we can express the load side voltage as,

$$
v_{b}=L_{o} \frac{d i_{L}}{d t}+v_{o}
$$

These voltages and current can be separated into the average and ripple components as follows:

$$
\begin{aligned}
& v_{b}=\bar{v}_{b}+\tilde{v}_{b} \\
& i_{L}=\bar{i}_{L}+\tilde{i}_{L}
\end{aligned}
$$




$$
v_{o}=\bar{v}_{o}+\tilde{v}_{o}
$$

Substituting (3)-(5) into (2) results in an output voltage equation in terms of average and ripple components:

$$
\bar{v}_{b}+\tilde{v}_{b}=L_{o} \frac{d \bar{i}_{L}}{d t}+L_{o} \frac{d \tilde{i}_{L}}{d t}+\bar{v}_{o}+\tilde{v}_{o}
$$

Separating average and ripple components on the right and left hand sides of (6), the followings are obtained

$$
\begin{aligned}
& \bar{v}_{b}=L_{o} \frac{d \bar{i}_{L}}{d t}+\bar{v}_{o} \\
& \tilde{v}_{b}=L_{o} \frac{d \tilde{i}_{L}}{d t}+\tilde{v}_{o}
\end{aligned}
$$

The ripple voltage across the output capacitor is much smaller than the ripple voltage across the output filter inductor and, therefore, (8) can be simplified into

$$
\tilde{v}_{b} \approx L_{o} \frac{d \tilde{i_{L}}}{d t}
$$

Based on (3) and (9), we can obtain the output ripple current as

$$
\tilde{i}_{L}=\frac{1}{L_{o}} \int\left(v_{b}-\bar{v}_{b}\right) d t
$$

The load voltage is equal to source voltage during active mode ( $\mathrm{S} 1$ and S2 ON), and equal to zero during freewheeling mode (S3 and S4 ON). The detailed output waveforms over one carrier period are shown in Figure 3(a). As the carrier frequency is much higher than the fundamental voltage frequency, the source voltage is assumed as a constant during one carrier period. Based on waveforms shown in Figure 3(a), we can express the load voltage as follow

$$
v_{b}= \begin{cases}v_{i} & \text { for } t_{o} \leq t \leq t_{1} \\ 0 & \text { for } t_{1} \leq t \leq t_{2}\end{cases}
$$

Based on this voltage expression, the average output voltage over one carrier period can be obtained as

$$
\bar{v}_{b}=\sqrt{2} \alpha E_{s} \sin \theta
$$




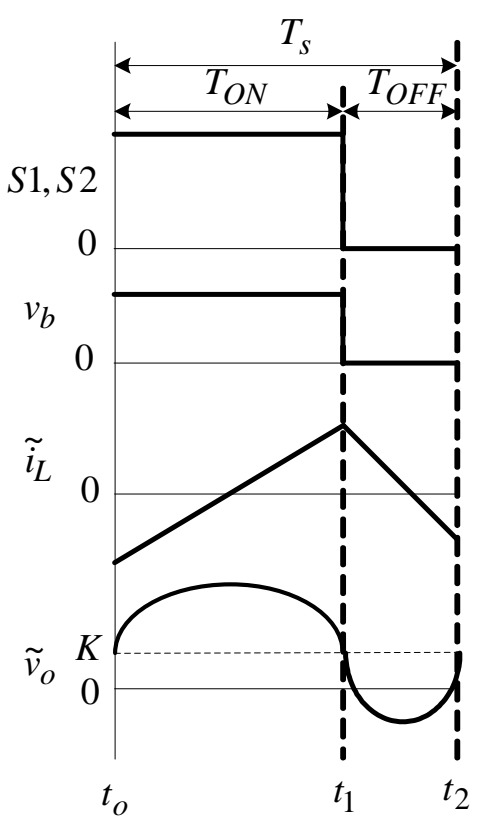

(a)

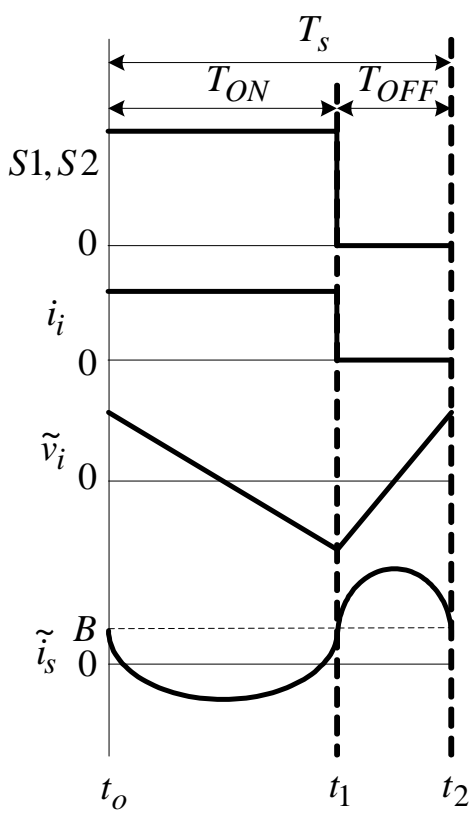

(b)

Figure 3 Waveform details. (a) Output and (b) input sides.

where

$$
\alpha=\frac{T_{O N}}{T_{s}}=\frac{v_{r e f}}{v_{t r i}}
$$

is the duty factor of the active switching devices. Based on (10) and (11), output current ripple can be expressed as

$$
\tilde{i}_{L}=\left\{\begin{array}{cc}
-\frac{\bar{v}_{b}}{L_{o}} \frac{T_{O F F}}{2}+\frac{v_{i}-\bar{v}_{b}}{L_{o}}\left(t-t_{o}\right) & \text { for } t_{o} \leq t \leq t_{1} \\
\frac{\bar{v}_{b}}{L_{o}} \frac{T_{O F F}}{2}-\frac{\bar{v}_{b}}{L_{o}}\left(t-t_{1}\right) & \text { for } t_{1} \leq t \leq t_{2}
\end{array}\right.
$$

The mean square value of output current ripple over one switching period can be obtained using following equation 


$$
\tilde{I}_{L}^{2}=\frac{1}{T_{s}} \int_{t_{o}}^{t_{o}+T_{s}} \tilde{i}_{L}^{2} d t
$$

Substituting (12) into (14) and the result is substituted into (15) and performing the integration the following result is obtained:

$$
\tilde{I}_{L}^{2}=\frac{1}{12}\left(\frac{v_{i} \alpha(1-\alpha)}{f_{s} L_{o}}\right)^{2}
$$

where $f_{s}=1 / T_{s}$ is switching frequency and $\alpha=T_{O N} / T_{s}$ is switch duty cycle.

The root mean square (rms) value of output current ripple over one fundamental period can be determined using the following equation

$$
\tilde{I}_{L, a v}=\sqrt{\frac{1}{2 \pi} \int_{0}^{2 \pi} \tilde{I}_{L}^{2} d \theta}
$$

Substituting (1) into (16) and the result is substituted into (17), the following is obtained after performing the integration

$$
\tilde{I}_{L, a v}=\frac{E_{s} \alpha(1-\alpha)}{2 \sqrt{3} f_{s} L_{o}}
$$

The above result shows that the output inductor current ripple is inversely proportional to the carrier frequency. This current ripple will be maximum when the duty factor is equal to half.

From Figure 1(a), the output filter capacitor current can be expressed as

$$
i_{L}=i_{C o}+i_{o}
$$

If the above currents are separated into the ripple and average components, output side current equation of ac chopper becomes

$$
\bar{i}_{L}+\tilde{i}_{L}=\bar{i}_{C o}+\tilde{i}_{C o}+\bar{i}_{o}+\tilde{i}_{o}
$$

Based on (19), the capacitor current ripple can be obtained as

$$
\tilde{i}_{C o}=\tilde{i}_{L}-\tilde{i}_{o}
$$

The load current ripple is usually much smaller than the inductor current ripple and, therefore, 


$$
\tilde{i}_{C o} \approx \tilde{i}_{L}
$$

Thus, the analysis of output inductor current ripple is also useful to determine the ripple current rating of the output filter capacitor.

The capacitor voltage ripple can be calculated using

$$
\tilde{v}_{o}=\frac{1}{C_{o}} \int \tilde{i}_{C o} d t=\frac{1}{C_{o}} \int \tilde{i}_{L} d t
$$

Substituting (14) into (23) and performing the integration, the following result are obtained

$$
\tilde{v}_{o}=\frac{\sqrt{2} E_{s} \sin \theta}{L_{o} C_{o}}\left\{\begin{array}{cc}
K-\frac{\alpha T_{\text {off }}}{2}\left(t-t_{o}\right)+\frac{1-\alpha}{2}\left(t-t_{o}\right)^{2} & \text { for } t_{o} \leq t \leq t_{1} \\
K+\frac{\alpha T_{\text {off }}}{2}\left(t-t_{1}\right)-\frac{\alpha}{2}\left(t-t_{1}\right)^{2} & \text { for } t_{1} \leq t \leq t_{2}
\end{array}\right.
$$

where

$$
K=\frac{\alpha^{3}(1-\alpha)-\alpha(1-\alpha)^{3}}{12}
$$

The mean square value of the capacitor voltage ripple over one carrier period can be obtained as

$$
\tilde{V}_{o}^{2}=\frac{1}{T_{s}} \int_{t_{o}}^{t_{o}+T_{s}} \tilde{V}_{o}^{2} d t
$$

Then, the rms output voltage ripple over one fundamental period can be obtained as

$$
\tilde{V}_{o, a v}=\sqrt{\frac{1}{2 \pi} \int_{0}^{2 \pi} \tilde{V}_{o}^{2} d \theta}
$$

Substituting (24) into (26) and the result is substituted into (27) and performing the integration, the result is

$$
\tilde{V}_{o, a v}=\frac{E_{s} \alpha(1-\alpha)}{12 f_{s}^{2} L_{o} C_{o}} \sqrt{\frac{1+2 \alpha-2 \alpha^{2}}{5}}
$$


The above result shows that the output voltage ripple is inversely proportional to the square of the carrier frequency. The expression of output voltage ripple is useful in designing the required output LC filter, which will be presented in the later section.

\subsection{Input Ripple Analysis}

In this analysis, it is assumed that output current is pure sinusoid, that is

$$
i_{L}=\sqrt{2} I_{L} \sin (\theta-\phi)
$$

where $\phi$ is the phase angle and $I_{L}$ are the rms value of load current, respectively. The chopper input current during one switching period can be written as

$$
i_{i}= \begin{cases}i_{L} & \text { for } t_{o} \leq t \leq t_{1} \\ 0 & \text { for } t_{1} \leq t \leq t_{2}\end{cases}
$$

The detailed input current waveforms over one carrier period is shown in Figure 3(b). As the carrier frequency is much higher than the fundamental output current frequency, the output current can be assumed as a constant during one carrier period.

Refer back to Figure 1(a), we can write the current relation in the input side of ac chopper as

$$
i_{s}=i_{C s}+i_{i}
$$

Similar to output ripple analysis, we can also separate the currents into the ripple and average components as followings

$$
\begin{aligned}
& i_{s}=\bar{i}_{s}+\tilde{i}_{s} \\
& i_{C s}=\bar{i}_{C s}+\tilde{i}_{C s} \\
& i_{i}=\bar{i}_{i}+\tilde{i}_{i}
\end{aligned}
$$

Substituting (32)-(34) into (31) results in

$$
\overline{i_{s}}+\tilde{i}_{s}=\bar{i}_{C s}+\tilde{i}_{C s}+\overline{i_{i}}+\tilde{i}_{i}
$$

Ripple and average components on the left and right hand sides of (35) must be equal, thus 


$$
\begin{aligned}
& \overline{i_{s}}={\overline{i_{C s}}}+{\overline{i_{i}}} \\
& \tilde{i}_{C s}=\tilde{i_{s}}-\tilde{i_{i}}
\end{aligned}
$$

The source current ripple is much smaller than other current ripples and, therefore, (37) can be simplified into

$$
\tilde{i}_{C s} \approx-\tilde{i}_{i}=\overline{i_{i}}-i_{i}
$$

Thus, analysis of chopper input current is important in sizing the ripple current rating of filter capacitor.

Based on (30), the average chopper input current is

$$
\bar{i}_{i}=\sqrt{2} \alpha I_{L} \sin (\theta-\phi)
$$

The rms value of this current is

$$
\bar{I}_{i}=I_{L} \alpha
$$

The mean square value of chopper input current over one carrier period can be obtained as:

$$
I_{i}^{2}=\frac{1}{T_{s}} \int_{0}^{T_{s}} i_{i}^{2} d t
$$

Substituting (30) into (41) and performing the integration, the result is

$$
I_{i}^{2}=\alpha i_{L}^{2}
$$

The rms value of the input current over one period of the fundamental frequency is:

$$
I_{i, r m s}=\sqrt{\frac{1}{2 \pi} \int_{0}^{2 \pi} \alpha i_{L}^{2} d \theta}
$$

Substituting (29) into (43) and performing the integration, the following is obtained

$$
I_{i, r m s}=I_{L} \sqrt{\alpha}
$$

Finally, the rms value of the ripple component of input current is 


$$
\tilde{I}_{i, r m s}=\sqrt{I_{i, r m s}^{2}-\bar{I}_{i}^{2}}=I_{L} \sqrt{\alpha(1-\alpha)}
$$

The rms values of chopper input current ripple and capacitor current ripple are the same.

The filter capacitor voltage ripple can be obtained as

$$
\tilde{v}_{i}=\frac{1}{C_{s}} \int \tilde{i}_{C s} d t=-\frac{1}{C_{s}} \int \tilde{i}_{i} d t=\frac{1}{C_{s}} \int\left(\bar{i}_{i}-i_{i}\right) d t
$$

Substituting (30) and (39) into (46) and performing the integration the result is as follow

$$
\tilde{v}_{i}=A \begin{cases}(\alpha-1)\left[-\left(t-t_{o}\right)+\frac{T_{o n}}{2}\right] & \text { for } t_{o} \leq t \leq t_{1} \\ -(\alpha-1) \frac{T_{o n}}{2}-\alpha\left(t-t_{1}\right) & \text { for } t_{1} \leq t \leq t_{2}\end{cases}
$$

where

$$
A=\left(\sqrt{2} I_{L} / C_{s}\right) \sin (\theta-\phi)
$$

The mean square value of capacitor voltage ripple over one switching period is

$$
\tilde{V}_{i}^{2}=\frac{1}{T_{s}} \int_{t_{o}}^{t_{o}+T_{s}} \tilde{v}_{i}^{2} d t
$$

Substituting (47) into (49) and performing the integration results in

$$
\tilde{V}_{i}^{2}=\frac{I_{L}^{2} \sin ^{2}(\theta-\phi)}{C_{s}^{2} f_{s}^{2} 12} \alpha^{2}(1-\alpha)^{2}
$$

The rms value of capacitor voltage ripple over one fundamental period can be calculated using the following equation

$$
\tilde{V}_{i, a v}=\sqrt{\frac{1}{2 \pi} \int_{0}^{2 \pi} \tilde{V}_{i}^{2} d \theta}
$$

Substituting (50) into (51) and performing the integration, the following is obtained 


$$
\tilde{V}_{i, a v}=\frac{I_{L}}{C_{S} f_{s}} \frac{\alpha(1-\alpha)}{2 \sqrt{3}}
$$

To analyze source current ripple, first let assume that the voltage source is free of ripple. The voltage equation in the input side of ac chopper can be expressed as

$$
e_{s}=L_{s} \frac{d i_{s}}{d t}+v_{i}
$$

Separating the above variables into the average and ripple components results in the following equations

$$
\begin{aligned}
& e_{s}=L_{s} \frac{d \bar{i}_{s}}{d t}+\bar{v}_{i} \\
& 0=L_{s} \frac{d \tilde{i}_{s}}{d t}+\tilde{v}_{i}
\end{aligned}
$$

Rearrange (55) will give us source current ripple equation, that is

$$
\tilde{i_{s}}=-\frac{1}{L_{s}} \int \tilde{v}_{i} d t
$$

Substituting capacitor voltage ripple in (47) into (56), the integration result is

$$
\tilde{i_{s}}=\frac{A}{2 L_{s}}\left\{\begin{array}{cc}
B+(1-\alpha)\left(t-t_{o}\right)^{2}-(1-\alpha)\left(t-t_{o}\right) T_{O N} & \text { for } t_{o} \leq t \leq t_{1} \\
B+(1-\alpha)\left(t-t_{1}\right) T_{O N}-\alpha\left(t-t_{1}\right)^{2} & \text { for } t_{1} \leq t \leq t_{2}
\end{array}\right.
$$

where

$$
B=(1-\alpha) \alpha\left(\frac{2 \alpha-1}{6}\right) T_{s}^{2}
$$

Based on (57), the mean square value of the source current ripple over one switching period can be obtained as follow

$$
\tilde{I}_{s}^{2}=\frac{1}{T_{s}} \int_{t_{o}}^{t_{o}+T_{s}} \tilde{i}_{s}^{2} d t
$$

Now the rms value of source current ripple over one fundamental period can be obtained by integrating (59) over its fundamental period: 


$$
\tilde{I}_{s, a v}=\sqrt{\frac{1}{2 \pi} \int_{0}^{2 \pi} \tilde{I}_{s}^{2} d \theta}
$$

Substituting (57) into (59) and performing the integration and the result is substituted into (60) and performing again the integration, the following result is obtained

$$
\tilde{I}_{s, a v}=\frac{I_{L} \alpha(1-\alpha)}{12 f_{s}^{2} L_{o} C_{o}} \sqrt{\frac{1+2 \alpha-2 \alpha^{2}}{5}}
$$

Eqs. (45), (52), and (61) are useful to design the input LC filter.

\section{Ripple Analysis of Three Phase AC Chopper}

Circuit topology for three phase ac chopper is shown in Figure 1(b). This topology is extended version of single phase ac chopper topology shown in Figure 1(a), since both topology have the same operation modes concept. In three phase ac chopper, the switching devices $\mathrm{S} 1, \mathrm{~S} 2$, and $\mathrm{S} 3$ receive $\mathrm{ON}$ signals and switching devices S4, S5, and S6 receive OFF signals during the active mode. On the other hand during the freewheeling mode, the switching devices $\mathrm{S} 1, \mathrm{~S} 2$, and $\mathrm{S} 3$ receive OFF signals and switching devices S4, S5, and S6 receive $\mathrm{ON}$ signals.

In order to simplify the output ripple analysis, the output circuit of three-phase chopper is redrawn as shown in Figure 4. The values of inductance and capacitance of the output LC filter must be changed accordingly. By using this figure, the output inductor current ripple of three phase ac chopper can be obtained in a similar way for output current ripple in single phase ac chopper. Since we use phase to phase voltage as reference, thus output current ripple expression in the delta connection will equal to output current ripple in single phase ac chopper except now the phase voltage term in (18) must be replaced with the phase to phase voltage in three phase systems. Thus, the inductor current ripple will be

$$
\tilde{I}_{L, a v}^{\Delta}=\frac{E_{l l} \alpha(1-\alpha)}{2 \sqrt{3} f_{s} L_{o}}
$$




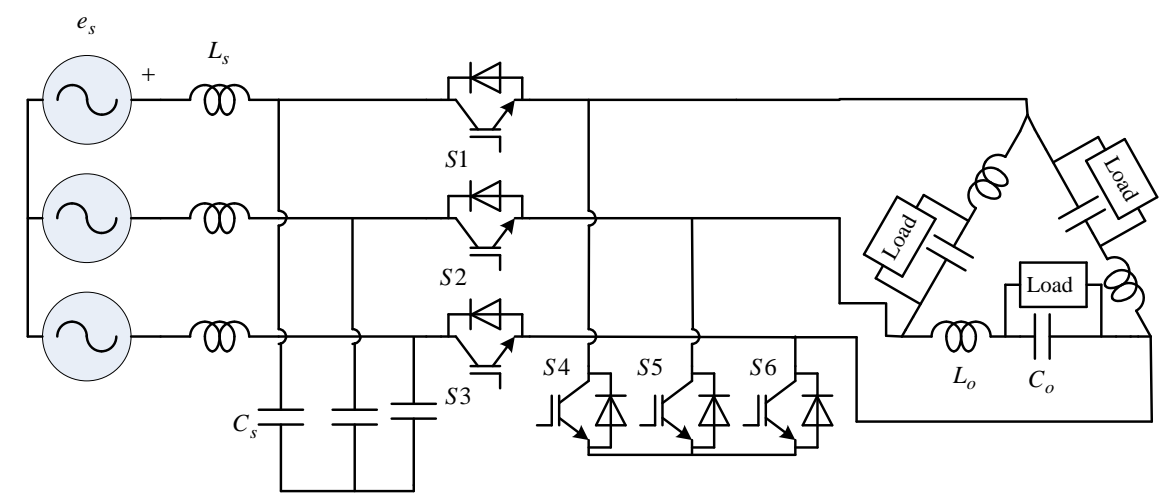

Figure 4 Three-phase ac chopper.

To obtain output inductor line current ripple, we can simply use $\sqrt{3}$ relation between phase current and line current in three phase system, thus we get the expression for output line current ripple as

$$
\tilde{I}_{L, a v}=\frac{E_{l l} \alpha(1-\alpha)}{2 \sqrt{3} f_{s} L_{o}}
$$

Similar method can be used to determine the output capacitor voltage ripple. The result is

$$
\tilde{V}_{o, a v}=\frac{E_{l l} \alpha(1-\alpha)}{12 f_{s}^{2} L_{o} C_{o}}\left(\frac{1+2 \alpha-2 \alpha^{2}}{5}\right)^{1 / 2}
$$

The input current and voltage ripples of three-phase chopper can be obtained by using the same equations as the ones of single-phase ac chopper.

\section{Determination of LC Filter}

In practice, only the output voltage ripple and source current ripple are specified. These ripples, however, are determined by the product of inductance and capacitance of the LC filter. Thus, unique values of inductance and capacitance of the filter cannot be determined. To solve this problem, an additional criterion based on minimum reactive power in the LC filter is used. Reactive power in the output LC filter can be expressed as

$$
P_{r}=\omega L_{o}\left(\bar{I}_{L}^{2}+\tilde{I}_{L, a v}^{2}\right)+\omega C_{o}\left(\bar{V}_{o}^{2}+\tilde{V}_{o, a v}^{2}\right)
$$


Since ripple components are much smaller than fundamental components, (65) is simplified to

$$
P_{r}=\omega L_{o} \bar{I}_{L}^{2}+\omega C_{o} \bar{V}_{o}^{2}
$$

Fundamental output current can be expressed as

$$
\bar{I}_{L}^{2}=\left(\operatorname{Re}\left\{I_{o}\right\}\right)^{2}+\left(\operatorname{Im}\left\{I_{o}\right\}-\omega C_{o} \bar{V}_{o}\right)^{2}
$$

Substituting (66) into (65), we can obtain the following expression:

$$
P_{r}=\omega L_{o}\left[\left(\operatorname{Re}\left\{I_{o}\right\}\right)^{2}+\left(\operatorname{Im}\left\{I_{o}\right\}-\omega C_{o} \bar{V}_{o}\right)^{2}\right\rfloor+\omega C_{o} \bar{V}_{o}^{2}
$$

Based on (28), the inductance of the output filter can be written as follow:

$$
L_{o}=\frac{E_{s} \alpha(1-\alpha)}{12 f_{s}^{2} C_{o} \tilde{V}_{o, a v}}\left(\frac{1+2 \alpha-2 \alpha^{2}}{5}\right)^{1 / 2}
$$

Substituting (69) into (68), the following reactive power expression can be obtained:

$$
P_{r}=\frac{\omega E_{s} F(\alpha)}{12 f_{s}^{2} C_{o} \tilde{V}_{o, a v}}\left[\left(\operatorname{Re}\left\{I_{o}\right\}\right)^{2}+\left(\operatorname{Im}\left\{I_{o}\right\}-\omega C_{o} \bar{V}_{o}\right)^{2}\right]+\omega C_{o} \bar{V}_{o}^{2}
$$

where

$$
F(\alpha)=\alpha(1-\alpha)\left(\frac{1+2 \alpha-2 \alpha^{2}}{5}\right)^{1 / 2}
$$

The optimum capacitance of the output filter can be obtained by solving the following equation:

$$
\frac{\partial P_{r}}{\partial C_{o}}=0
$$

After the capacitance of the filter is obtained then the inductance can be calculated by using (69). A similar method is used to determine the optimum inductance and capacitance of the input LC filter. 


\section{Experimental Results}

An experimental setup for single phase ac chopper as shown in Figure 1(a) has been built to verify the derived expressions. This experimental setup uses transistor modules as switching devices, operated at $1 \mathrm{kHz}$ of switching frequency. An inductance of $30 \mathrm{mH}$ and a capacitance of $360 \mathrm{uF}$ are used as the input LC filter to ensure good input source waveforms, while an inductance of $10 \mathrm{mH}$ and a capacitance of $250 \mathrm{uF}$ are used as the output LC filter. A resistor of $5 \Omega$ is used as the load of single phase ac chopper. Input voltage is fixed at $35 \mathrm{~V}(50 \mathrm{~Hz})$, while the output voltage is variable as a function of the reference voltage.

Figure 5 shows the resulted output inductor current and voltage waveforms. It can be seen that the inductor current is almost sinusoidal. The output voltage has a form as expected. In order to determine the ripple component, the waveform over one fundamental period is captured by using a digital oscilloscope. The result is then processed by using a digital computer to calculate the ripple component.

Figures 6 and 7 show the calculated and experimental results of output inductor current and capacitor voltage ripples. The solid line is the calculated result and square mark indicates the experimental results. These figures show clearly the agreement between the calculated and experimental results.

Figures 8 and 9 show the calculated and experimental results of input voltage and source current ripples, respectively. Once again, these results show clearly the agreement between the calculated and experimental results.

In order to further verify the proposed analysis method, an extensive simulation by using PSIM software has been done. Based on simulated results, the calculated results will be accurate (error is less than 5\%) if the followings are fulfilled:

i) The switching frequency is more than 10 times the fundamental output frequency.

ii) The ripple or harmonic content is less than 20 percent.

iii) The resonant frequency of the LC filter is less than one third of the switching frequency. 


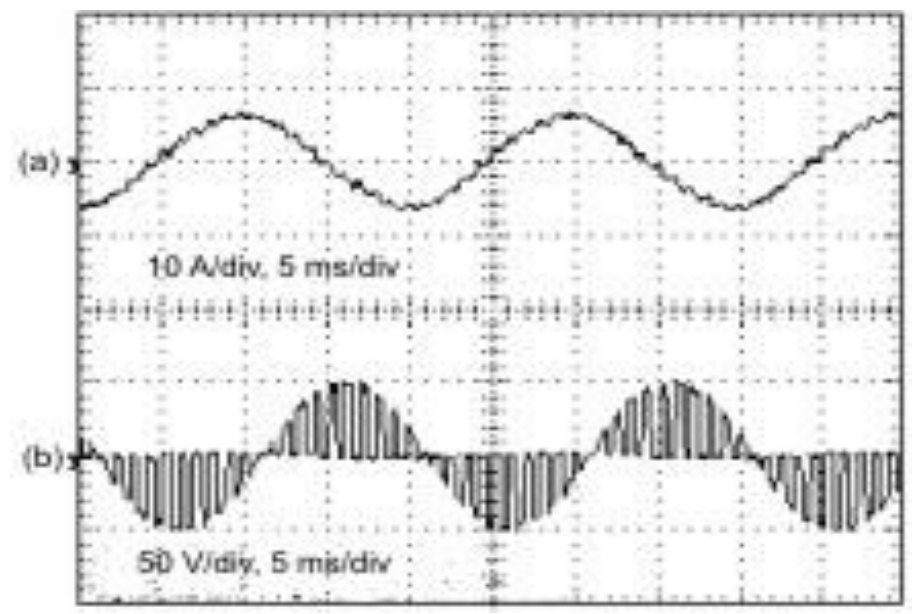

Figure 5 Output (a) current and (b) voltage waveforms.

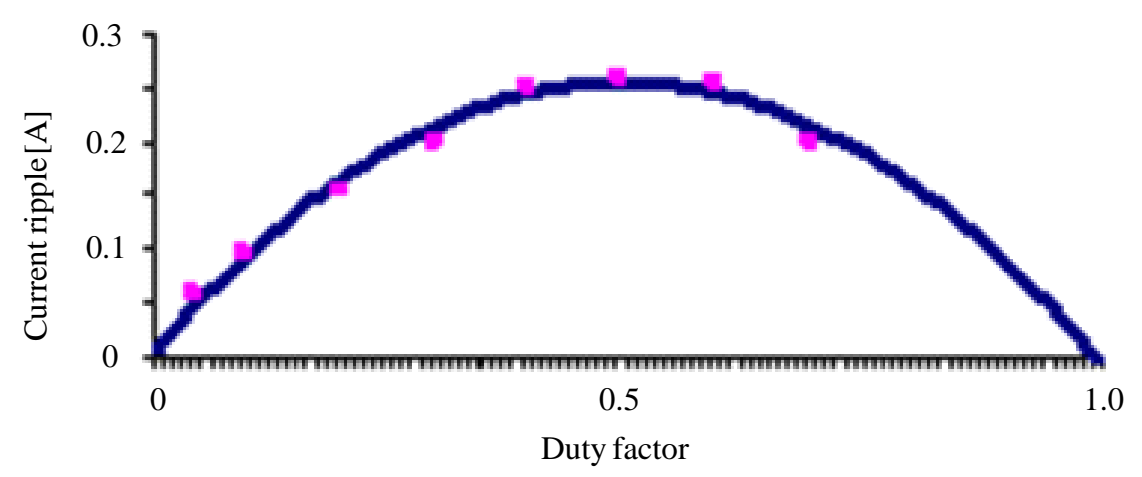

Figure 6 Experimental and calculated results of output inductor current ripple.

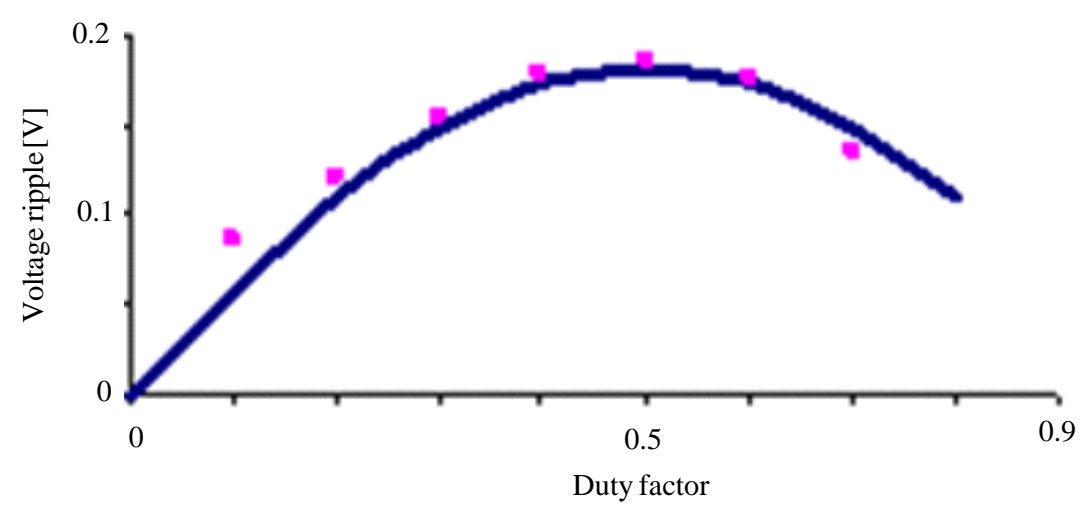

Figure 7 Experimental and calculated results of output voltage ripple. 


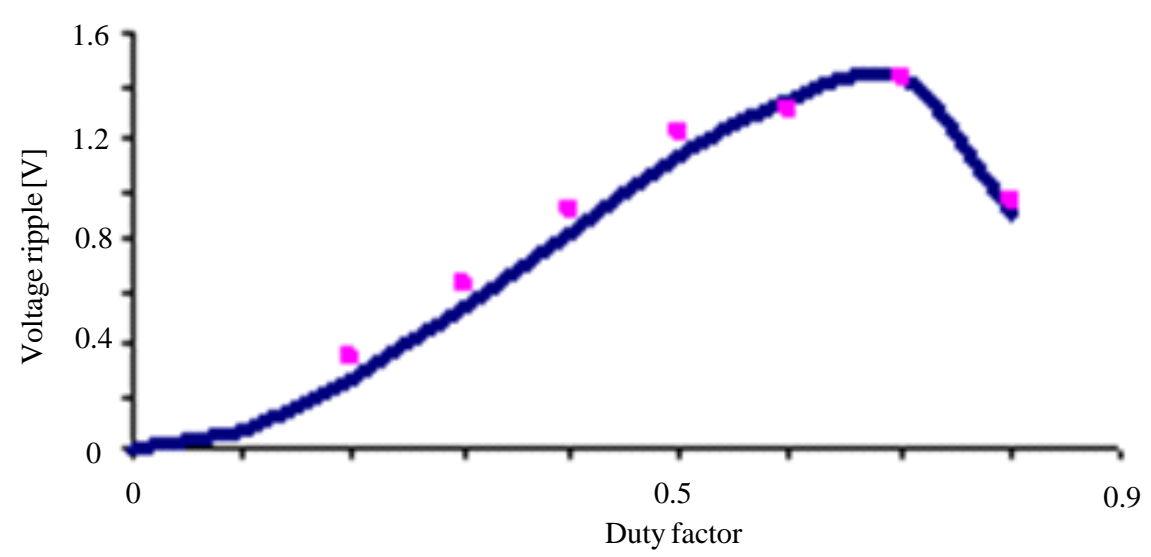

Figure 8 Experimental and calculated results of input voltage ripple.

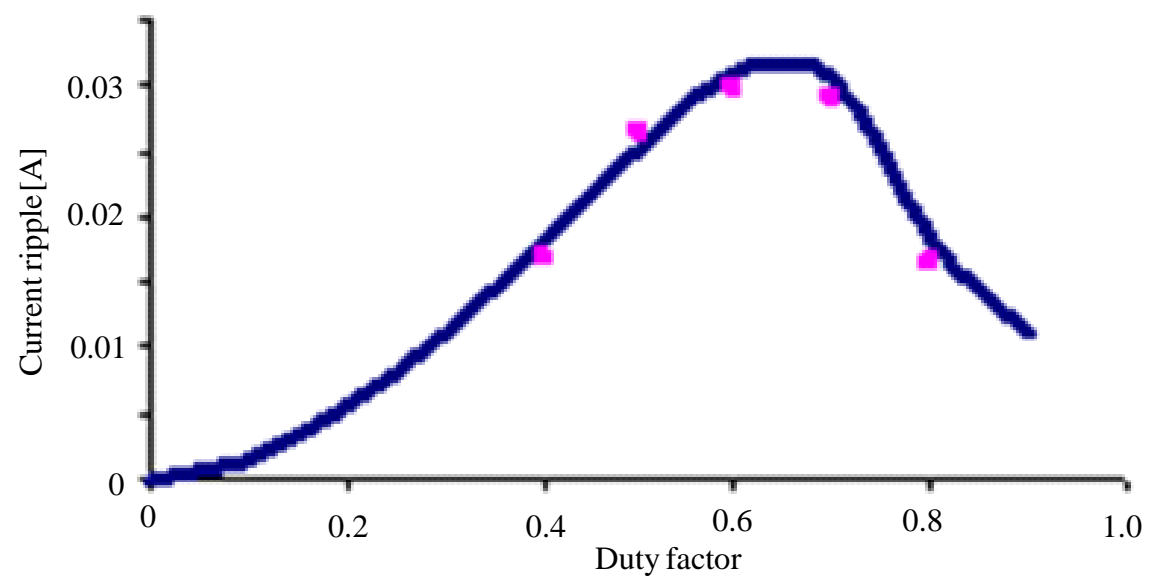

Figure 9 Experimental and calculated results of source current ripple.

\section{Conclusion}

In this paper, analytical expressions for input and output side ripples of both single-phase and three-phase PWM AC choppers have been derived. The output inductor current ripple and input capacitor voltage ripple are varies inversely proportional to the switching frequency. The output capacitor voltage ripple and source current ripple are varies inversely proportional to the square of switching frequency. The proposed analysis method is very useful in the design of input and output LC filters of PWM AC choppers. A design criterion based on the minimum reactive power of $\mathrm{LC}$ filter is proposed. The proposed analysis method has been verified by experimental results. 


\section{References}

[1] Addoweesh, K.E. \& Mohammadein, A.L., Microprocessor Based Harmonic Elimination in Chopper Type AC Voltage Regulators, IEEE Trans. Power Electr., 5, pp. 191-200, April 1990.

[2] Ahmed, N.A., Amei, K. \& Sakui, M., A New Configuration of SinglePhase Symmetrical PWM AC Chopper Voltage Controller, IEEE Trans. Ind. Appl., 46, pp. 942-952, Oct. 1999.

[3] Jang, D.H. \& Choe, G.H., Improvement of Input Power Factor in AC Choppers Using Asymmetrical PWM Technique, IEEE Trans. Ind. Appl., 42, pp. 179-185, Apr. 1995.

[4] Srinivasan, S. \& Venkataramanan, G., Comparative Evaluation of PWM AC-AC Converters, Proc. IEEE PESC, pp. 529-535, June 1995.

[5] Kwon, B.H., Min, B.D. \& Kim, J.H., Novel Topologies of AC Chopper, IEE Proc. Eletr. Power. Appl., 143, July 1996.

[6] Venkataramanan, G., A Family of PWM Converters for Three Phase AC Power Conditioning, Proc. Conf. IEEE Power Electronic, Drives, and Energy System for Industrial Growth, pp. 572-577, June 1996.

[7] Lefeuvre, E., Meynard, T. \& Viarouge, P., Robust Two-Level and Multilevel PWM AC Choppers, Proc. Conf. EPE, pp. 1-8, 2001.

[8] Fedyczak, Z., Strzelecki, R. \& Benysek, G., Single-phase PWM AC/AC Semiconductor Transformer Topologies and Applications, Proc. IEEE PESC, pp. 1048-1053, June 2002.

[9] Petry, C.A., Fagundes, J.C. \& Barbi, I., New Direct Ac-Ac Converters Using Switching Modules Solving the Commutation Problem, Proc. of IEEE ISIE, pp. 864-869, July 2006.

[10] Ben-Yaakov, S., Hadad, Y. \& Diamantstein, N., A Four Quadrant HF AC Chopper with no Deadtime, Proc. IEEE APEC, pp. 1461-1465, March 2006. 